\title{
Childhood Absence Epilepsy
}

National Cancer Institute

\section{Source}

National Cancer Institute. Childhood Absence Epilepsy. NCI Thesaurus. Code C128189.

A common generalized epilepsy syndrome occurring in children, characterized by absence seizures of short duration. The cause of the syndrome is presumed to be genetic. Genes which are associated with the condition are GABRB3, GABRG2, GABRA1, CACNA1H, GABRA1, and GABRA5. 